\title{
AC 2011-1483: STUDENT PERCEPTION OF LECTURE VIDEO USE AS A MEANS TO INCREASE TIME FOR IN CLASS PROBLEM SOLVING APPLICATIONS
}

\section{Dale S.L. Dolan, California Polytechnic State University}

Dale S.L. Dolan is an Assistant Professor of Electrical Engineering at Cal Poly with experience in renewable energy projects, education, power electronics and advanced motor drives. He received his BSc in Zoology in 1995 and BEd in 1997 from the University of Western Ontario. He received the BASc in Electrical Engineering in 2003, MASc. in Electrical Engineering in 2005 and $\mathrm{PhD}$ in Electrical Engineering in 2009 all from the University of Toronto. He is past chair of Windy Hills Caledon Renewable Energy, past chair of the OSEA (Ontario Sustainable Energy Association) Board and was an executive chair of the 7th World Wind Energy Conference 2008 (WWEC 2008). He is currently a member of the management committee for the Ontario Green Energy Act Alliance in the midst of implementation of the most progressive renewable energy policy in North America. His research interests involve sustainable/renewable energy generation, wind power generation, smart grid technology, power systems, electromagnetics, power electronic applications for distributed generation, grid connection impacts of renewable generation, energy policy promoting widespread implementation of sustainable power generation, sustainable energy project economics and sustainability of technologies.

\section{Vladimir I Prodanov, California Polytechnic State University (Cal Poly), San Luis Obispo, CA 93407}

Vlad Prodanov received MS and Ph.D. degrees, both in electrical engineering, from the State University of New York at Stony Brook in 1995 and 1997 respectively. He was with Bell Laboratories, Lucent Technologies from 1997 until 2000 and Agere Systems (now LSI Logic) from 2000 to 2004. From 2004 to 2008 he was member of MHI Consulting, New Providence, NJ. Currently, he is an assistant professor with EE Dept., Cal Poly, San Luis Obispo, CA. Mr. Prodanov has worked on various electronic systems for communications and contributed to two dozen peer-reviewed publications, three book chapters, and seventeen granted US patents. He has taught circuit design at SUNY Stony Brook and Columbia University NY City. Dr. Prodanov is co-recipient of the Best Poster Paper Award at the 2006 IEEE Custom Integrated Conference and his doctoral work has been recognized in 1997 by Stony Brook Chapter of Sigma Xi with Excellence in Research Award.

Taufik Taufik, California Polytechnic State University 


\title{
Student Perception of Lecture Video Use as a Means to Increase Time for in Class Problem Solving Applications
}

\begin{abstract}
The purpose of this study is to examine student perceptions of lecture video use as a means to increase available time for in class problem solving in a teaching and learning context. A portion of face to face lectures was replaced with prerecorded lecture video whose viewing was assigned for homework. The freed lecture period was used for additional in class problem solving development, without sacrificing the theory and background that is fundamental. In order to assess the effectiveness of the change in format, student perception was assessed through an anonymous online survey. The survey was given at the completion of a course. The data was collected in two electrical engineering courses. The first was a required sophomore level circuits course and the second was a senior technical elective power electronics course. The survey is a tool to both determine the value of the additional face to face problem solving time and the effectiveness of the video lecture as seen by the student. Students will be asked if they enjoyed the class more than a traditional lecture course and also if they feel they were able to perform at a higher level due to the format. They will also be surveyed to determine if full use was made of both the video lecture and the in class problem solving sessions. The responses showed strong student support for the format and students perceived that they were able to learn material more effectively. There was little difference in the proportions of responses from the different courses despite the different level of students and different instructors. Only student perception was measured and actual student performance data was not assessed as a fair control group could not be established without imposing a perceived disadvantage on one group of students. In total there were 90 students surveyed across the two courses.
\end{abstract}

\section{Introduction}

Engineering students often express their desire to spend more face-to-face time solving problems and getting more practical application examples. There is limited time in the course of scheduled lectures to do this and any additional time spent would take away from the lecture delivery of theory and background required to successfully solve problems. Although some sample problems are traditionally solved during class, many more are assigned for students to complete on their own. This leaves students to develop problem solving skills mostly on their own, often without a model of an organized approach. In the past it has been difficult to provide many options to students outside of traditional face to face instructional time whether this takes place in a conventional lecture or in a tutorial/recitation session. A number of institutions do not have formal tutorial sessions associated with lecture sessions and as such do not have the flexibility to do much of the problem solving that can take place in these sessions. With the advancement and accessibility of many new communication and interactive technologies a number of new 
possibilities are now available that can easily be implemented to supplement student learning in these courses. There have been several studies that have implemented some of these possibilities in the hopes of improving student performance [1],[2],[3].

This study proposes to replace a portion of face to face lectures with prerecorded lecture video assigned for homework. This enables the freed lecture period to be used for additional in class problem solving development, without sacrificing the theory and background that is fundamental. In order to assess the effectiveness of the change in format, student perception will be assessed through an anonymous online survey. The survey will be given at the completion of the course. This survey will seek to both determine the value of the additional face to face problem solving time and the effectiveness of the video lecture. Students will be asked if they enjoyed the class more than a traditional lecture course and also if they feel they were able to perform at a higher level due to the format. They will also be surveyed to determine if full use was made of both the video lecture and the in class problem solving sessions. Although assessment of student's performance would be ideal a suitable control could not be obtained that would allow comparison of grades with and without the presumed benefit of video lectures. In the future this may be attempted although the fairness of creating a control group which an instructor believes to be at a disadvantage must first be addressed.

\section{Survey Results}

The survey created to assess student perception of the video lecture is included in Appendix A. The survey includes 15 sets of five level Likert items to which the students were asked to respond. The data was collected for two electrical engineering courses. The first was a required sophomore level circuits course and the second was a senior technical elective power electronics course. Both of these courses have significant problem solving components and were both seen as good candidates for the lecture video experiment. In total there were 90 students surveyed across the two courses. Student response to the survey was voluntary and anonymous. Students that chose to participate in the quiz showed a high rate of survey completion. Of the 90 students who responded to the survey, 1 chose not to answer question 3, 2 chose not to answer question 6 and 3 chose not to answer question 12 . The other 12 questions were answered by all participants. Since responses were anonymous, no link can be made to the performance of an individual student in the class and their responses. A summary of responses for each individual question is displayed in Figures 1 to Figure 3. Each specific question is displayed below the corresponding figure. 


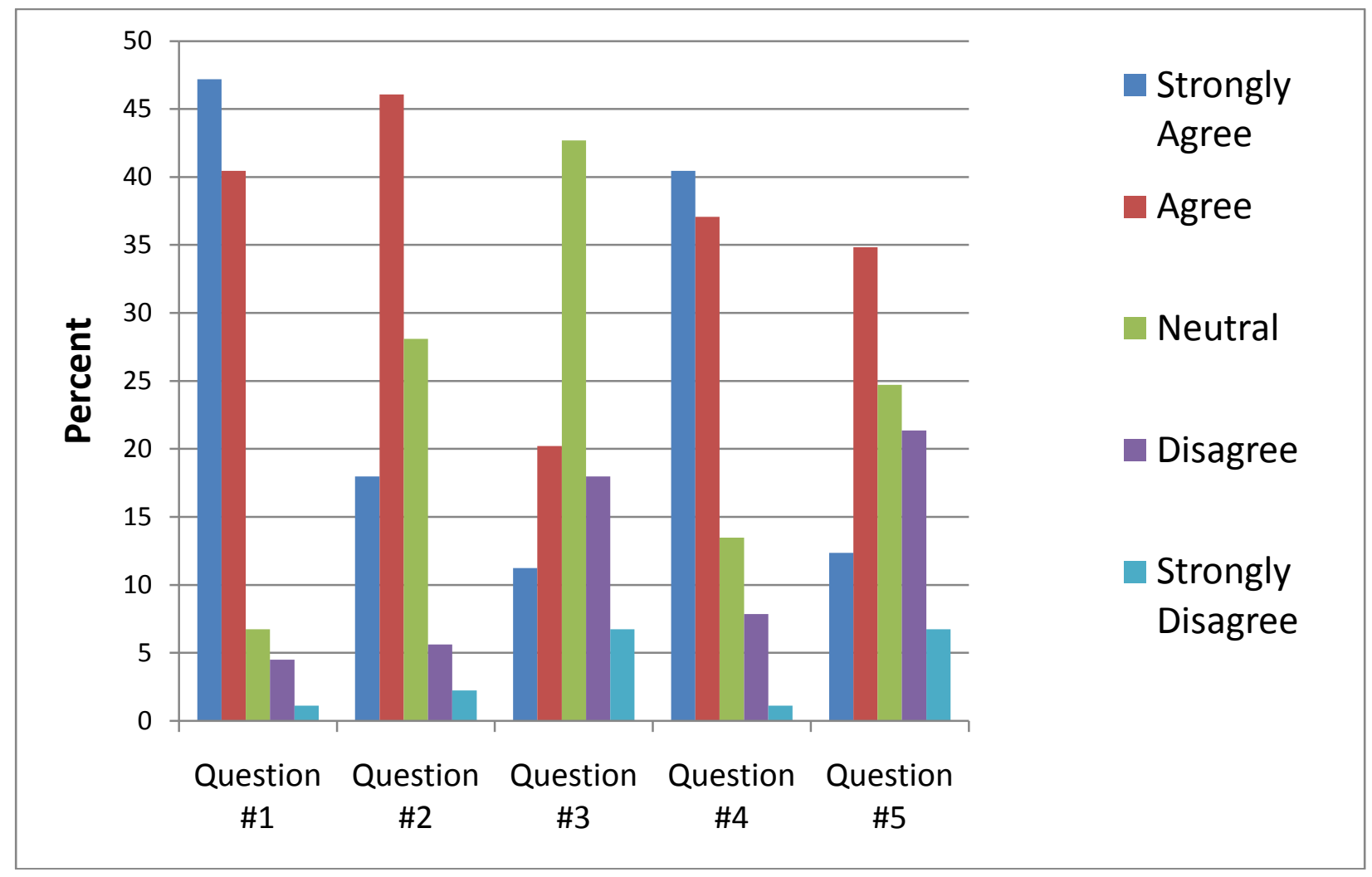

Figure 1. Survey Results - Question \#1-5.

Question 1: I found the video lecture useful.

Question 2: The video was a faster way to cover lecture material than a face to face lecture

Question 3: The video was a more effective way to cover lecture material than a face to face lecture.

Question 4: I was able to learn more from the video lecture since I was able view at my own pace and to rewind and review portions I did not understand the first time.

Question 5: I missed being able to ask questions during the video lecture.

As shown in figure 1, Figure 2 and Figure 3, responses to questions were generally polarized indicating general agreement among students as to their views on the effectiveness of the method. As shown in Figure 1, questions 1 and 2, a vast majority of the students found the video lectures useful and their value in being a faster way to cover lecture material than in the traditional face to face setting. In some qualitative statements students were particularly cognisant of the ability to use the video lecture to learn at their own pace and to review areas when and where required as opposed to being tied to the pace of the entire class, which in many cases is too fast and in others too slow. This can be seen from the results of question 4. Students were closer to neutral on the video lecture being a more effective way to deliver a lecture. Question 3 was designed assuming that the majority would feel that face to face lecture was the most effective, ignoring time constraints. Many student missed being able to ask questions during the lecture but the consensus was closer to neutral. This may be in part due to the fact that many students do not regularly ask questions during lecture and leave it to a few students who feel comfortable doing so. 


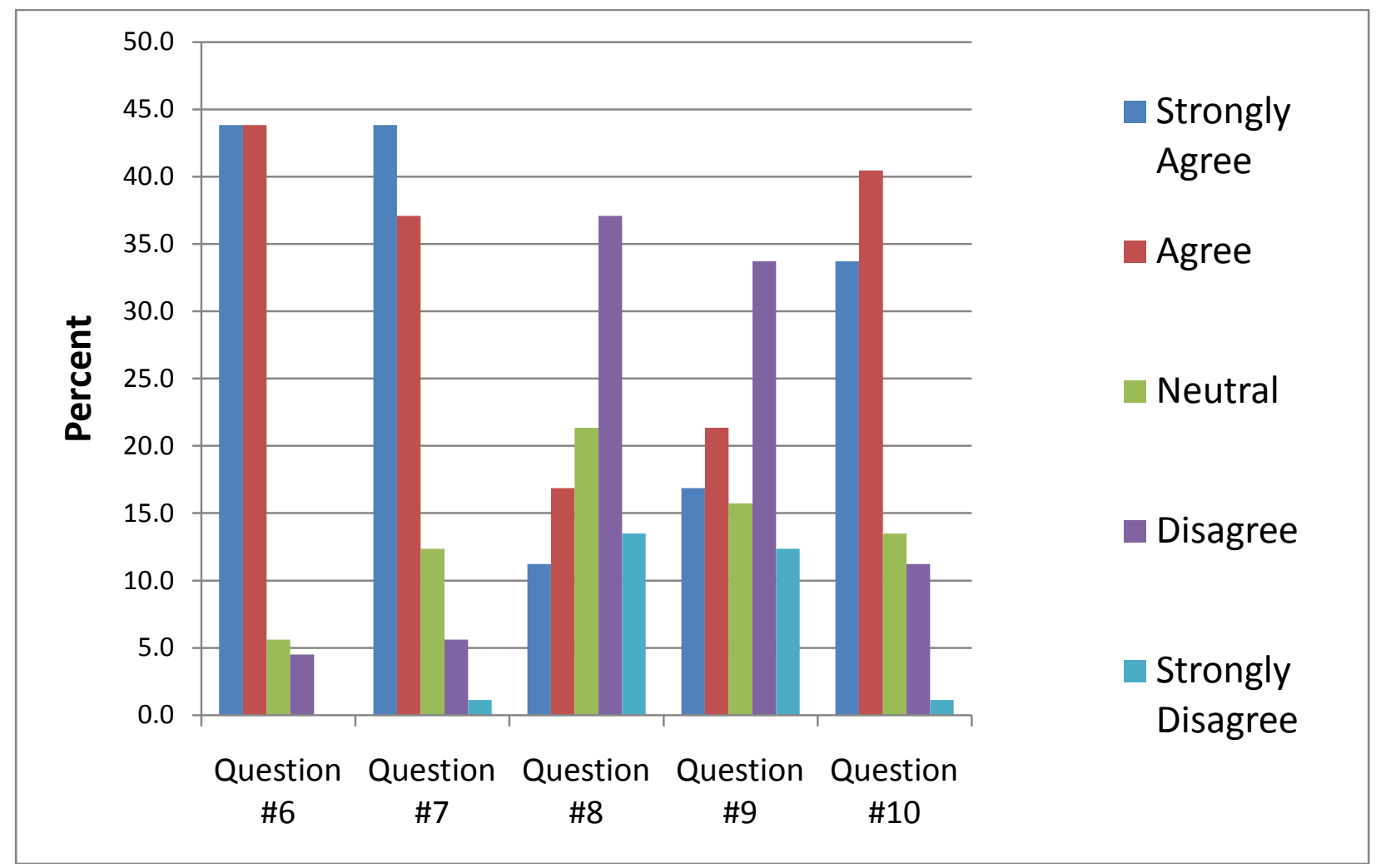

Figure 2. Survey Results - Question \#6-10.

Question 6: I found the problem solving examples in class useful.

Question 7: If time constraints were not an issue, I would prefer both lecture and problem solving examples to occur face to face in class time.

Question 8: Taking into consideration time constraints I would prefer all lecture to take place, face to face in class and problem solving examples to be covered by textbook examples and posted solutions.

Question 9: Taking into consideration time constraints I would prefer only problem solving examples in face to face class time and all lecture to take place via recorded video.

Question 10: Taking into consideration time constraints I would prefer some lectures to take place via recorded video and the time made available to be used for problem solving examples.

Figure 2 is intended to demonstrate the desires of students in relation to division of class time devoted to problem solving and that devoted to lecture. An overwhelming majority expressed the value of having problem solving sessions in class and would prefer both lecture and problem solving to occur in face to face time if time constraints were not an issue. However it seemed that over $70 \%$ approved of the shift of some lecture to video to allow more problem solving time as a viable alternative given time considerations. Although students did not experience the cases described in Question 8 or 9 it is clear that the majority do not prefer all lecture or all video lecture even if that allows the entire face to face time to be devoted to problem solving. 


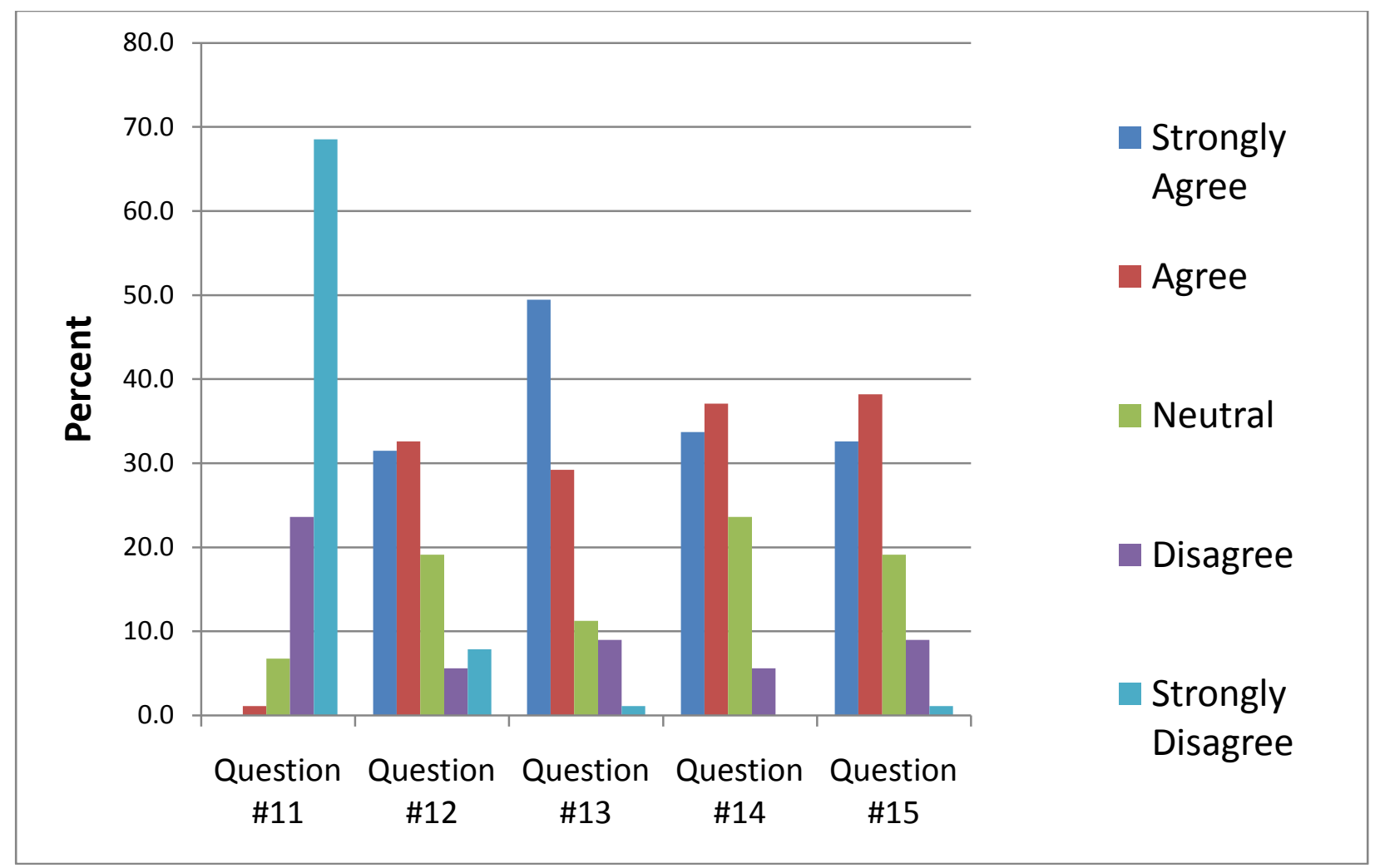

Figure 3. Survey Results - Question \#11-15.

Question 11: If a number of lectures were presented via video recording, I would watch none of the videos.

Question 12: If a number of lectures were presented via video recording, I would watch some of the videos.

Question 13: If a number of lectures were presented via video recording, I would watch all of the videos..

Question 14: If a number of lectures were presented via video recording, I would watch the videos before the corresponding problem solving session.

Question 15: I would watch the videos more than once to review the material.

Close to $80 \%$ of students responded that they would watch all videos and a large group said they would watch some of the videos. This is one key concern that students would just ignore the videos and miss out on a significant source of the theory behind the problem solving. Many students indicated that they had watched and that they would watch videos more than once. This could alleviate some of the time demands imposed on faculty as well as improving understanding and retention, although this study has no way of evaluating or assessing the validity of this claim. 


\section{Conclusion}

The use of lecture video as a means to increase available time for in class problem solving in a teaching and learning context has been well received by a large number and varied group of students. A portion of face to face lectures was replaced with prerecorded lecture video whose viewing was assigned for homework. The freed lecture period was used for additional in class problem solving development. The effectiveness of the change in format was assessed through an anonymous online survey in which students indicated strong support of the approach. Many felt they were able to learn more effectively and gain a better understanding of conceptual material as well as problem solving experience. It is unclear whether this was actually the case or if this was merely perception. It is the intention of the authors to continue this method and collect additional data from other electrical engineering core and technical elective courses over the next several years to determine if the trends are consistent across courses and levels or if there is some link to the type of course or experience level of the student. In a comparison of two courses it was found that there was close agreement between their responses although this data has not been displayed separately due to the similarity. However it would be preferred to compare two courses of similar level (sophomore versus senior) and different areas (power, circuits, communications) as well as courses of similar areas and different levels.

\section{References}

1. E. Berger, "Podcasting in Engineering education: A preliminary study of content, student attitudes, and impact", Innovate 4 (1) 2007. http://www.innovateonline.info/index.php?view=article \&id=426

2. D. Zhang, L. Zhou, R.O. Briggs and J.F.Nunamaker. Jr, "Instructional video in e-learning: Assessing the impact of interactive video on learning effectiveness", Information and Management 43 (1) (2006), pp. 15-27

3. P. Herder, E. Subrahmanian, S. Talukdar, A. Turk, W. Westerberg, "S". "The use of video-taped lectures and web-based communications in teaching: A distance-teaching and cross-Atlantic collaboration experiment", European Journal of Engineering Education, Vol. 27, Issue 1, pp. 39 - 48, March 2002 


\section{Appendix A}

\section{LECTURE VIDEO SURVEY}

This questionnaire is designed to assess your perceptions of the use of lecture videos as a means to increase time for in class problem solving applications. Please answer the questions as honestly as possible and to the best of your ability. Participation is voluntary, and all responses will be kept anonymous. Thanks for your time!

1. Please indicate on a scale of 1 to 5 your level of agreement with the following statements. ( 1 being strongly disagree and 5 being strongly agree). Circle one.

\begin{tabular}{|c|c|c|c|c|c|}
\hline & \begin{tabular}{|l|} 
Strongly \\
Disagree
\end{tabular} & Disagree & Neutral & Agree & $\begin{array}{c}\text { Strongly } \\
\text { Agree }\end{array}$ \\
\hline I found the video lecture useful. & 1 & 2 & 3 & 4 & 5 \\
\hline $\begin{array}{l}\text { The video was a faster way to cover lecture material than a } \\
\text { face to face lecture. }\end{array}$ & 1 & 2 & 3 & 4 & 5 \\
\hline $\begin{array}{l}\text { The video was a more effective way to cover lecture } \\
\text { material than a face to face lecture. }\end{array}$ & 1 & 2 & 3 & 4 & 5 \\
\hline $\begin{array}{l}\text { I was able to learn more from the video lecture since I was } \\
\text { able view at my own pace and to rewind and review portions } \\
\text { I did not understand the first time. }\end{array}$ & 1 & 2 & 3 & 4 & 5 \\
\hline $\begin{array}{l}\text { I missed being able to ask questions during the video } \\
\text { lecture. }\end{array}$ & 1 & 2 & 3 & 4 & 5 \\
\hline I found the problem solving examples in class useful. & 1 & 2 & 3 & 4 & 5 \\
\hline $\begin{array}{l}\text { If time constraints were not an issue, I would prefer both } \\
\text { lecture and problem solving examples to occur face to face } \\
\text { in class time. }\end{array}$ & 1 & 2 & 3 & 4 & 5 \\
\hline $\begin{array}{l}\text { Taking into consideration time constraints I would prefer all } \\
\text { lecture to take place, face to face in class and problem } \\
\text { solving examples to be covered by textbook examples and } \\
\text { posted solutions. }\end{array}$ & 1 & 2 & 3 & 4 & 5 \\
\hline $\begin{array}{l}\text { Taking into consideration time constraints I would prefer } \\
\text { only problem solving examples in face to face class time and } \\
\text { all lecture to take place via recorded video. }\end{array}$ & 1 & 2 & 3 & 4 & 5 \\
\hline $\begin{array}{l}\text { Taking into consideration time constraints I would prefer } \\
\text { some lectures to take place via recorded video and the time } \\
\text { made available to be used for problem solving examples. }\end{array}$ & 1 & 2 & 3 & 4 & 5 \\
\hline $\begin{array}{l}\text { If a number of lectures were presented via video recording, I } \\
\text { would watch none of the videos. }\end{array}$ & 1 & 2 & 3 & 4 & 5 \\
\hline
\end{tabular}




\begin{tabular}{|c|c|c|c|c|c|}
\hline $\begin{array}{l}\text { If a number of lectures were presented via video recording, I } \\
\text { would watch some of the videos. }\end{array}$ & 1 & 2 & 3 & 4 & 5 \\
\hline $\begin{array}{l}\text { If a number of lectures were presented via video recording, I } \\
\text { would watch all of the videos. }\end{array}$ & 1 & 2 & 3 & 4 & 5 \\
\hline $\begin{array}{l}\text { If a number of lectures were presented via video recording, I } \\
\text { would watch the videos before the corresponding problem } \\
\text { solving session. }\end{array}$ & 1 & 2 & 3 & 4 & 5 \\
\hline $\begin{array}{l}\text { I would watch the videos more than once to review the } \\
\text { material. }\end{array}$ & 1 & 2 & 3 & 4 & 5 \\
\hline
\end{tabular}

Please write any additional comments or important points you feel were missed in the survey.

Thank you for your time and participation! 